\title{
WHEN CAN NEURAL TISSUE BE TRANSPLANTED?
}

\author{
C. N. SVENDSEN and S. B. DUNNETT \\ Cambridge
}

\begin{abstract}
Although corneal transplantation is now a widely used technique in ophthalmology, there have been no attempts to clinically transplant retinal ganglion (RGCs) which are damaged through trauma or disease. This is due to a number of factors, the most important of which is that axons growing out from transplanted tissue would have to grow long distances to reach their normal targets within the central nervous system (CNS). The major problem is that the adult CNS is known to support such longdistance axon growth and regeneration only rather poorly. However, recent experimental studies in the rat have shown that axotomised RGCs can regenerate axons over long distances through environments more conducive to growth. For example, RGC axons will grow through a bridge of peripheral nerve to make appropriate connections within the superior colliculus from both a functional and anatomical perspective. ${ }^{1}$ Furthermore, other studies have shown that axons from embryonic retinal transplants placed over the brainstem of neonatal rats can innervate the pretectal nucleus and superior colliculus and are capable of driving a pupillary response pathway in the host rat. ${ }^{2,3}$ These results suggest that under certain conditions embryonic neural transplants or induced neuronal regeneration in remaining RGCs can restore some visual function. Although massive practical and experimental issues lie ahead before these grafting methods can be considered in a clinical setting, there is at least potential for future neural replacement therapy in patients where the connections between the eye and the brain are destroyed.

But when can neural tissue be transplanted? Perhaps the most extensive literature, both clinical and experimental, with regard to neural transplants comes from studies involving transplantation in Parkinson's disease. In this disorder, dopaminergic

From: MRC Cambridge Centre for Brain Repair and Department of Experimental Psychology, University of Cambridge, England.

Correspondence to: C. N. Svendsen, MRC Cambridge Centre for Brain Repair and Department of Experimental Psychology, University of Cambridge, Cambridge CB2 3EB, UK. Fax: 01223 331174.
\end{abstract}

neurons of the substantia nigra slowly begin to die for unknown reasons leaving the patient trapped in a body which has lost control of movement. During the early stages of the disease, patients respond well to LDOPA which allows them freedom of movement again for short periods of time. However, the drug becomes less and less effective as the disease progresses and has a number of serious side effects. The most obvious way to treat Parkinson's disease would be to somehow replace the dopamine neurons with new ones - a strategy that has been used very successfully for kidney, heart and corneal diseases where new tissues taken from recently deceased donors have been transplanted to replace old or diseased ones in the affected patient. Unfortunately, it is not possible to use nerve cells from the adult after death as they are no longer functional following removal of the brain. However, in animal experiments fetal CNS tissue has been shown to survive dissociation and transplantation into the adult brain. These neural grafts differentiate and can send out axons over fairly long distances. ${ }^{4}$ There have also been a number of clinical trials where dopaminergic neurons taken from aborted human fetal tissue have been transplanted into the brains of patients with Parkinson's disease. Although these trials are still under way, preliminary results suggest that in many cases these cells can survive for extended periods of time and often lead to significant clinical improvement. $^{5,6}$

The major limitations to these transplantation therapies for Parkinson's disease, or other diseases where neurons may be required to repair a specific deficit, revolve around the ethics associated with the use of human fetal tissue and the practical problems of achieving a reliable high level of graft survival and growth. Certain countries do not allow fetal tissue to be used in any human transplantation studies while others do not allow elective abortions to occur under any circumstances. For example, during the Reagan and Bush administrations in the United States, government funding for all work on human aborted fetal tissue for transplantation was terminated. 
However, the recent Clinton administration has reversed this ruling and several multi-centre clinical trials of dopamine nerve cell transplants for patients with Parkinson's disease are now under way in the United States. In addition to the complex moral issues, there are further practical concerns. Using the present techniques, only about $5-10 \%$ of dopamine cells survive transplantation. Consequently, in order to achieve good functional response, it has been found necessary to use donor tissue from four or five fetuses implanted into each side of the brain in patients with Parkinson's disease. The additional requirements that the donor tissue must be fresh and undamaged raises substantial problems for obtaining a reliable supply of donor tissue other than in very particular research contexts. In most hospitals around the world this is to all intents and purposes impractical if not impossible. Even in those few centres where it is attempted, the quality of the fetal tissue varies enormously and patients from the different centres show inconsistent levels of improvement.

One strategy to address these problems of availability of suitable donor tissue is to use new methods of growing, selecting and expanding cells in the test tube for subsequent transplantation. We have found that precursor cells located within the developing rat and human embryonic brain can be isolated and induced to proliferate rapidly in culture when exposed to epidermal growth factor (EGF) under suitable culture conditions. These pluripotent precursors are predominantly stem cells and give rise to astrocytes, oligodendrocytes and neurons. Although EGF-responsive CNS precursor cells have been described previously by Weiss and colleagues in Canada using mouse tissue, ${ }^{7}$ rat and human precursor cells have proved more difficult to grow in the test tube. However, using a modified culture medium we have been able to expand human and rat precursor cells from the rat and human embryonic brain ${ }^{8}$ and have found that a proportion of the cells survive transplantation into the adult rat brain and develop into mature neurons. ${ }^{9}$ In the search for alternative neural tissue for transplantation, these results may hold some promise for the future since these EGF-driven precursor cells can be grown and proliferated in culture such that one human fetus can potentially give rise to millions of pluripotent cells which can be frozen, stored in small batches and distributed to hospitals where patients are being treated. As these precursors cells are able to develop into many different types of mature cell of the CNS, they may also be useful for transplantation studies in other diseases such as multiple sclerosis, where glial cells which insulate the nerves are needed rather than the dopamine neurons required for Parkinson's disease. However, the signals which control the phenotypic development of precursor cells are still only poorly understood and are the subject of intense investigation.

Although we have found that human CNS precursor cells can be expanded in culture while retaining the ability to survive and mature in to nerve cells when transplanted into the adult rat brain, a current major limitation of this method with regard to using these cells for treating Parkinson's disease is the small number of dopamine neurons which normally develop from the grafted precursors. However, it may be possible to modify these cells in culture prior to transplantation by using gene transfer methods or specific growth factors to direct the division of neural precursors into specific lineages for their differentiation into dopamine neurons. In support of the viability of this strategy, recent studies have found that pure neuronal progenitors can be expanded from EGF-generated precursors or primary embryonic brain cultures using high concentrations of fibroblast growth factor (FGF: Svendsen and Rossor, unpublished observations ${ }^{10,11}$ ).

In parallel to these studies on EGF-generated precursors other laboratories have been using various types of immortalised cell lines which retain neuronal characteristics upon differentiation. The lines are generated by inserting a viral oncogene into developing neuronal precursors which induce the cells to continue dividing indefinitely provided permissive conditions exist. Under non-permissive conditions these cells differentiate into neuronal-like cells and have been shown to integrate well with host tissue following grafting. ${ }^{12,13}$ Like the expanded precursor cell populations, immortalised cells may provide an alternative source of tissue for transplantation instead of primary neuronal tissue from aborted fetuses. However, one caveat with immortalised cell lines is the threat of tumour formation as it is difficult to exclude completely the possibility that the viral insert may overcome its non-permissive environment in some way and return to the proliferative state, leading to tumour formation in the host brain.

In conclusion, the feasibility of neural transplantation to replace populations of neurons lost in human neurological disease has been well demonstrated in the early clinical trials in Parkinson's disease. The limitations of grafting neuronal tissue at present stem in large part from the need to use only embryonic donors, resulting in substantial moral, ethical and practical problems which need to be overcome before these procedures become routine. However, new ways of expanding neuronal precursors in culture may lead to a more available source of neurons for grafting into the damaged CNS. If transplantation of RGCs ever becomes a clinical 
possibility, these methods of growing neurons may provide an ideal source of tissue for such trials.

Our research in this area has been supported by grants from the Medical Research Council and the Hereditary Disease Foundation.

Key words: EGF-expanded precursor cells, Neural transplantation, Nigral grafts, Parkinson's disease.

\section{REFERENCES}

1. Rasminsky M, Bray GM, Aguayo AJ. Anatomic and functional correlates of the regeneration of retinotectal projections in adult animals. In: Dunnett SB, Bjorklund A, editors. Functional neural transplantation. New York: Raven Press, 1994:437-50.

2. Lund RD, Hankin MH, Sefton AJ, Perry VH. Conditions for optic axon outgrowth. Brain Behav Evol 1988;31:218-26.

3. Coffey PJ, Lund RD, Rawlins JNP. Retinal transplantmediated learning in a conditioned suppression task in rats. Proc Natl Acad Sci USA 1989;86:7248-9.

4. Bjorklund A. Neural transplantation: an experimental tool with clinical possibilities. TINS 1991;14:319-22.

5. Lindvall O, Widner $\mathrm{H}$, Rehncrona S, Brundin $\mathrm{P}$, Odin $\mathrm{P}$, Gustavii B, et al. Transplantation of fetal dopamine neurons in Parkinson's disease: one year clinical and neurophysiological observations in 2 patients with putaminal implants. Ann Neurol 1992;31:155-65.

6. Lindvall O. Neural transplantation in Parkinson's disease. In: Dunnett SB, Björklund A, editors. Func- tional neural transplantation. New York: Raven Press, 1994:103-37.

7. Reynolds BA, Tetzlaff W, Weiss S. A multipotent EGFresponsive striatal embryonic progenitor cell produces neurons and astrocytes. J Neurosci 1992;12:4565-74.

8. Svendsen CN, Fawcett J, Bentlage C, Dunnett SB. Increased survival of rat EGF-generated CNS precursor cells using B27 supplemented medium. Exp Brain Res, 1995;102:407-14.

9. Svendson CN, Clarke DJ, Fawcett JW, Haque N, Dunnett SB. Grafting of cultured human and rat EGF-responsive progenitor cells into the striatum of 6-OHDA lesioned rats. Soc Neurosci Abstr 1994; 20:205.3.

10. Ray J, Peterson DA, Schinstine M, Gage FH. Proliferation, differentiation, and long-term culture of primary hippocampal neurons. Proc Natl Acad Sci USA 1993;90:3602-6.

11. Vescovi AL, Reynolds BA, Fraser DD, Weiss S. bFGF regulates the proliferative fate of unipotent (neuronal) and bipotent (neuronal/astroglial) EGF-generated CNS progenitor cells. Neuron 1993;11:951-66.

12. Renfranz PJ, Cunningham MG, McKay RDG. Regional specific differentiation of the hippocampal stem cell line HiB5 upon implantation into the developing mammalian brain. Cell 1991;66:713-29.

13. Snyder EY, Deitcher DL, Walsh C, Arnold-Aldea S, Hartweig EA, Cepko CL. Multipotent neuronal cell lines can engraft and participate in development of mouse cerebellum. Cell 1992;68:33-51. 